\title{
BMJ Global Health Cooperative societies: a sustainable platform for promoting universal health coverage in Bangladesh
}

\author{
Abdur Razzaque Sarker, ${ }^{1,2}$ Marufa Sultana, ${ }^{1}$ Rashidul Alam Mahumud ${ }^{1}$
}

To cite: Sarker AR, Sultana M, Mahumud RA. Cooperative societies: a sustainable platform for promoting universal health coverage in Bangladesh. BMJ Global Health 2016;1: e000052. doi:10.1136/ bmjgh-2016-000052

Received 21 March 2016 Revised 23 May 2016 Accepted 25 May 2016

CrossMark

\footnotetext{
${ }^{1}$ Health Economics \&

Financing Research, International Centre for Diarrhoeal Disease Research, Bangladesh (icddr,b), Dhaka, Bangladesh

${ }^{2}$ University of Strathclyde, Glasgow, UK
}

Correspondence to Abdur Razzaque Sarker; arazzaque@icddrb.org
Bangladesh is among the most densely populated countries in the world and has enjoyed a steady annual economic growth of 5-6\% for more than a decade. ${ }^{1}$ According to the Bangladesh economic review, the incidence of poverty has declined considerably from $56.7 \%$ in $1991-1992$ to $24.8 \%$ in $2015 .^{2}$ The demographic structure of Bangladesh is changing more rapidly. The population pyramid is slightly narrower at the bottom than the middle, and the youngest age group constitutes more than half of the population. ${ }^{3}$ In addition, the increasing per capita income has resulted in heightened demand for public and private sector health services. Bangladesh has made good progress in almost all of the health-related Millennium Development Goals (MDGs). ${ }^{4}$ A new universal set of goals-the Sustainable Development Goals (SDGs) - to eradicate poverty, fight inequality and injustice, protect the earth and advance prosperity by 2030 was launched on 1 January $2016 .{ }^{5}$ While it seems that the SDGs are less health oriented than the MDGs, the SDGs have the potential to be a game changer in global health, given that achieving universal health coverage (UHC) is among the core objectives of the health SDG. Based on the UHC theme, all people who need health services should receive them without undue financial hardship and should have $100 \%$ financial protection from out-of-pocket payments by $2030 .{ }^{6}{ }^{7}$

Although introducing UHC remains challenging in resource-poor settings, countries such as Thailand, Rwanda and Mexico have proved that UHC is not only achievable by high-income countries only, but that commitment and political obligation also make it possible to advance on the path towards UHC. Thailand, Rwanda and Mexico have shown that political prioritisation of UHC has yielded major gains in health and financial protection for their citizens. ${ }^{8}$ However, Bangladesh is not starting from zero. The

\section{Summary box}

Achieving Universal Health Coverage is among the core objectives of the health Sustainable Development Goals, and making healthcare affordable to everyone is fundamental to achieving Universal Health Coverage.

- Cooperative societies are autonomous groups of persons who voluntarily cooperate for their common economic interest, based on the values of self-help, self-responsibility, democracy and equality, equity and solidarity.

- There are 190360 cooperatives in Bangladesh, and the total individual enrolees are 10333310 (with about 160 million people covered when spouses or dependents of enrolees are taken into account). Given this large pool, cooperative societies could be a platform to engage a large number of people regarding healthcare financing.

- Cooperative societies act as a risk management strategy for members, working on the basic principle of risk pooling during illness. This riskpooling mechanism can mitigate the consequences of dependence on out-of-pocket payments to finance healthcare, thereby facilitating the move towards Universal Health Coverage.

government of the People's Republic of Bangladesh already designed a healthcare financing strategy for 2012-2032 to move towards the long-term objective of UHC. Meanwhile, a community-based health scheme combined with microhealth insurance is being tested in different parts of the country. The coverage of existing community-based health insurance or microinsurance prepayment schemes currently serve as an interim measure for social health protection and the plan is that they will gradually expand towards greater coverage of the entire population. ${ }^{9}$ A holistic approach is necessary because population coverage is among the key dimensions of UHC, that is, nobody should be left out of the shelter of health coverage. In light of this dimension, 
cooperative societies have already proved an important entry point for achieving UHC. ${ }^{10}$

A cooperative is an autonomous group of persons who voluntarily cooperate for their common economic interest, based on the values of self-help, self-responsibility, democracy and equality, equity and solidarity. ${ }^{11}$ It is a social institution in which different groups of people, irrespective of their social, racial, political or religious status, come forward to think and work together to promote their socioeconomic development, sharing ownership and making decisions democratically. The goals of cooperatives include the economic development of the members, building up unity and promoting social integration, and cooperation among the members of the group. Through development programmes, cooperative members learn the relationship between serving their own needs and the viability of organisations, including interpersonal awareness about health and family welfare on a large scale. In addition to economic and social development, cooperatives play an important role in accessing health services for Bangladesh's vast population. ${ }^{12} 13$

Cooperatives in Bangladesh are organised under the Department of Cooperatives in the Ministry of Local Government and Rural Development of Bangladesh. According to the latest report, there are 190360 cooperatives in Bangladesh, among which 22 are at the national level, whereas 1160 and 189181 are in the form of central-level and primary-level cooperatives. ${ }^{14}$ The total enrollees of cooperatives are 10333 310. Notably, this number includes only members, and not their spouses or dependents. Hence, it can be argued that much of the about 160 million Bangladeshi population is covered in some manner under the umbrella of these cooperative societies. Cooperatives play a significant role in access to equitable healthcare service use at an affordable price, introducing health plans along with their other functions. ${ }^{10} 1516$ Again, by introducing this business model in a cooperative, there may be scope for lowincome communities to increase their income and the affordability of purchasing any good or service.

The Healthcare Financing Strategy of Bangladesh proposed extending health coverage to the entire population, together with mechanisms for financing. ${ }^{9}$ Cooperative societies can provide a platform to engage a large number of people regarding healthcare financing. Cooperative societies act as a risk management strategy for members, working on the basic principle of riskpooling during illness. It is possible for cooperatives to consult with public health facilities and other healthcare providers for affordable inpatient care. It is also possible that a public health authority could ensure health service for all members of particular cooperative with an agreed payment basis. This risk-pooling mechanism will mitigate the consequences of dependence on out-of-pocket payments and finance healthcare, moving towards universal coverage.

The government of Bangladesh is committed to spreading the cooperative movement across the country to ensure the socioeconomic and cultural emancipation of the people. ${ }^{17}$ In addition, the Department of Cooperatives is preparing a comprehensive marketing plan that will facilitate the production, storage, processing, transportation and marketing of products provided by the members of cooperatives. ${ }^{14}$ However, although cooperative societies represent a strong entry point, there remain some common problems, such as internal conflict among members, lack of democratic practice, lack of leadership, lack of professional management, political interference and lack of investment, which can hinder them from taking advantage of new opportunities. ${ }^{11}$ There is no shortcut to UHC. A high level of political commitment, a high societal value placed on health and an effective evidence-based process for policy development and implementation are essential to achieving UHC. ${ }^{8}$ Therefore, policymakers, including the Department of Cooperatives and the relevant ministry, might adopt initiatives to promote the concept of UHC. In addition, it is necessary to explore how to best create intersectoral policies to address health needs sustainably and thereby achieve the SDGs in Bangladesh, involving the cooperatives to ensure healthy lives and promote well-being for all, at all ages, by 2032.

\section{Handling editor Seye Abimbola}

Twitter Follow Abdur Sarker at @Razzaque_Sarker

Contributors ARS, MS and RAM designed and planned the study. The study was coordinated and analysed by ARS, MS and RAM. All authors critically reviewed and have given final approval of the manuscript.

Competing interests None declared.

Provenance and peer review Not commissioned; externally peer reviewed.

Data sharing statement No additional data are available.

Open Access This is an Open Access article distributed in accordance with the Creative Commons Attribution Non Commercial (CC BY-NC 4.0) license, which permits others to distribute, remix, adapt, build upon this work noncommercially, and license their derivative works on different terms, provided the original work is properly cited and the use is non-commercial. See: http:// creativecommons.org/licenses/by-nc/4.0/

\section{REFERENCES}

1. Government of Bangladesh. Bangladesh National Health Accounts 1997-2012. Dhaka, Bangladesh: Health Economics Unit, Ministry of Health and Family Welfare, Government of the People's Republic of Bangladesh, 2015.

2. Government of Bangladesh. Bangladesh Economic Review 2015. Dhaka: Ministry of finance, Government of the People Republic of Bangladesh, 2015. http://www.mof.gov.bd/en/index.php? option=com_content\&view=article\&id=340\&ltemid=1 (accessed 3 Mar 2016).

3. BDHS. Bangladesh Demography and Health Survey-2011. National Institute of Population Research and Training, Dhaka Bangladesh and Mitra and Associates, 2013.

4. MOHFW. Health Bulletin 2015. Dir. Gen. Heal. Serv., 2015. http:// www.dghs.gov.bd

5. UNDP. United Nations. Sustainable Development Solutions Network. Transforming Our World: the 2030 Agenda for Sustainable Development, 2016. http://bit.ly/1P1zfHH (accessed 5 Mar 2016).

6. WHO/World Bank Group. Monitoring progress towards universal health coverage at country and global levels: framework, measures and targets. Geneva, Switzerland, 2014.

7. WHO. Health systems financing: the path to universal health coverage. World Health Report 2010. Geneva, Switzerland, 2010. 
8. Pablos-Mendez A, Cavanaugh K, Ly C. The new era of health goals: universal health coverage as a pathway to the sustainable development goals. Health Syst Reform 2016;2:15-17.

9. MOHFW. Expanding social protection for health: towards universal coverage, health care financing strategy 2012-2032. Dhaka, Bangladesh: Health Economics Unit, Ministry of Health and Family Welfare, Government of the People's Republic of Bangladesh, 2012.

10. Meng Q, Fang $\mathrm{H}$, Liu X, et al. Consolidating the social health insurance schemes in China: towards an equitable and efficient health system. Lancet 2015;386:1484-92.

11. Islam MJ, Azim M, Karim MM, et al. An overview on co-operative societies in Bangladesh. Eur J Bus Manag 2014;6:33-40.

12. Yu H. Universal health insurance coverage for 1.3 billion people: what accounts for China's success? Health Policy 2015;119:1145-52. doi:10.1016/j.healthpol.2015.07.008
13. Zou J, Yang W, Cook DM, et al. New cooperative medical financing policy and hospitalization in rural China: multi-stage cross-sectional surveys. Int Health 2016;8:59-66.

14. Government of Bangladesh. Department of cooperatives, LGRD, Dhaka, Bangladesh: 2015. http://www.coop.gov.bd/site/page/ 77e5c950-c266-474c-9752-49738a216dfa/At-a-glance (accessed 3 Feb 2016).

15. Yu B, Meng Q, Collins C, et al. How does the New Cooperative Medical Scheme influence health service utilization? A study in two provinces in rural China. BMC Health Serv Res 2010;10:116.

16. Borzaga C, Fazzi L. Civil society, third sector, and healthcare: the case of social cooperatives in Italy. Soc Sci Med 2014:123:234-41.

17. Hasina S. 39th National Cooperative Day held in Bangabandhu International Conference Centre in Dhaka, Bangladesh, 2010. http:// www.coop.gov.bd/National_coop_day.htm (accessed 5 Jul 2014). 